
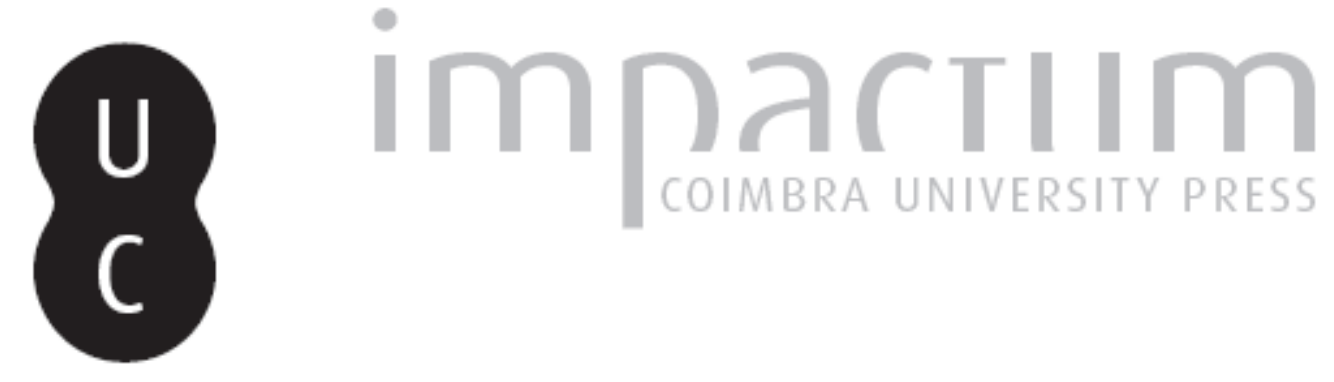

\title{
Los incendios forestales en España: panorama actual e interés de los tipos de tiempo para conocimiento de su frecuencia y del riesgo de grandes incendios
}

Autor(es): $\quad$ Ferreras Chasco, Casildo

Publicado por: Associação Portuguesa de Riscos, Prevenção e Segurança

URL

persistente:

URI:http://hdl.handle.net/10316.2/40099

DOI:

DOI:https://doi.org/10.14195/1647-7723_8_4

Accessed : $\quad$ 26-Apr-2023 11:36:25

A navegação consulta e descarregamento dos títulos inseridos nas Bibliotecas Digitais UC Digitalis, UC Pombalina e UC Impactum, pressupõem a aceitação plena e sem reservas dos Termos e Condições de Uso destas Bibliotecas Digitais, disponíveis em https://digitalis.uc.pt/pt-pt/termos.

Conforme exposto nos referidos Termos e Condições de Uso, o descarregamento de títulos de acesso restrito requer uma licença válida de autorização devendo o utilizador aceder ao(s) documento(s) a partir de um endereço de IP da instituição detentora da supramencionada licença.

Ao utilizador é apenas permitido o descarregamento para uso pessoal, pelo que o emprego do(s) título(s) descarregado(s) para outro fim, designadamente comercial, carece de autorização do respetivo autor ou editor da obra.

Na medida em que todas as obras da UC Digitalis se encontram protegidas pelo Código do Direito de Autor e Direitos Conexos e demais legislação aplicável, toda a cópia, parcial ou total, deste documento, nos casos em que é legalmente admitida, deverá conter ou fazer-se acompanhar por este aviso.

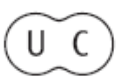




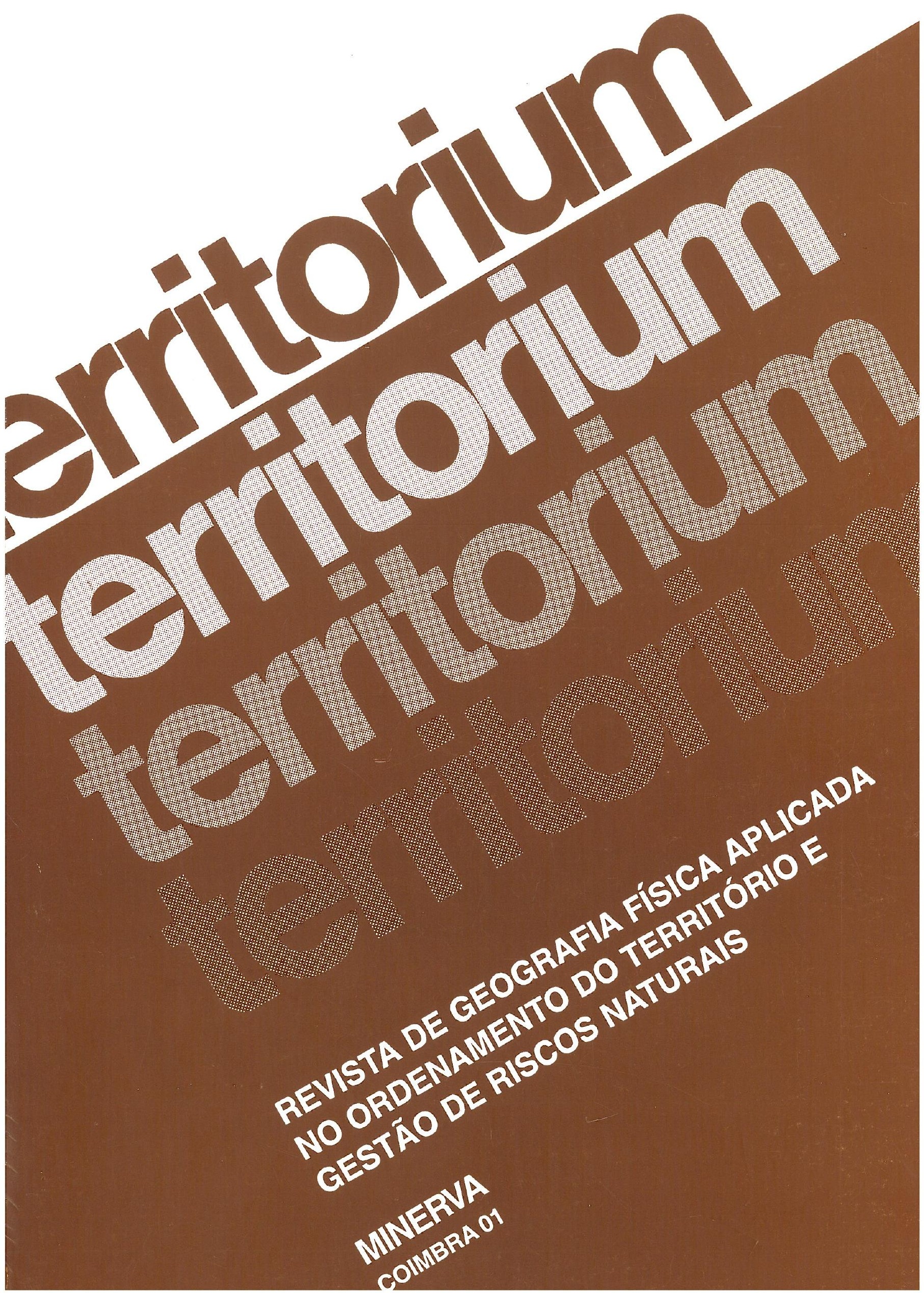




\title{
Los incendios forestales en España. Panorama actual e interés de los tipos de tiempo para conocimiento de su frecuencia y del riesgo de grandes incendios
}

\author{
Casildo Ferreras Chasco *
}

\begin{abstract}
Resumo:
Faz-se uma breve revisão da evolução e situação presente e das linhas de investigação sobre os incêndios florestais em Espanha, com especial atenção aos grandes incêndios (de mais de 500 ha), analisa-se a relação entre os incêndios activos cada dia e os grandes incêndios e as características do tempo. Constata-se uma boa relação entre incêndios activos cada dia e tipos de tempo, no entanto, nos grandes incêndios esta correlação é menos estreita, por apresentar também uma forte dependência de outros factores.

Palavras chave:

Riscos de incêndios florestais, incêndios florestais em Espanha, tipos de tempo.

Résumé:

On fait une courte révision de l'évolution et de la situation actuelle, ainsi que des lignes de recherche sur les incendies de forêt en Espagne, avec une attention spéciale aux grands incendies (au dessus de 500 ha), on analyse la relation entre les incendies actifs chaque jour et les grands incendies et types de temps. On constate une bonne correspondence entre incendies actifs chaque jour et types de temps, mais dans les grands incendies cette correlation est moins étroite, car elle présente aussi une forte dépendence d'autres facteurs.

Mots clés:

Risques d'incendies de forêt, incendies de forêt en Espagne, types de temps.

\section{Abstract:}

The evolution and present situation and lines of research of forest fires in Spain are briefly shown with special attention on big fires (above 500 has) and the relation between weather characteristics and number of daily active fires and big fires is analysed. A good correlation between active fires and weather types is proved, but in the big fires this correlation is less closely related, because they may be also strongly dependent of other factors. Key words:

Forest fire hazards and risks, forest fires in Spain, weather types.
\end{abstract}

\section{Introducción. Evolución reciente e importan- cia de los incendios.}

En el último medio siglo los incendios forestales han adquirido en España una frecuencia y magnitud que, aun no habiendo llegado a la gravedad que han alcanzado en algunos otros países, no cabe duda les ha convertido en uno de los principales problemas medioambientales y un importantísimo riesgo para el medio natural. Los datos disponibles desde 1960 permiten apreciar su magnitud y tendencia creciente tanto en número como en superficie afectada.

En los años sesenta no se llegaba a 2.000 incendios por año, pero su número fue creciendo rápidamente a lo largo de los años setenta y ochenta hasta rebasarse

\footnotetext{
* Professor. Departamento de Análisis Geográfico Regional y Geografía
} Física de la Universidad Complutense. Madrid. España. sistemáticamente los 10.000 fuegos registrados en los noventa, llegando a superarse algunos años los 20.000 . Fue 1989 el primer año en rebasar esta cifra con 20.593, pero el máximo corresponde a 1995 con 25.827 incendios. Parte de este incremento se debe indudablemente a una contabilidad más precisa de los pequeños incendios, pues como han señalado diversos autores "hasta los años ochenta... no se incluían los que afectaban a montes privados, así como los menores a un determinado número de hectáreas" (MARTIN \& otros, 1998). Pese a estas limitaciones estadísticas es evidente que, aun descontando los que en los datos de los últimos años por no llegar a 1 ha se califican de "conatos", la tendencia sigue siendo alcista.

En cuanto a superficie también hay una clara tendencia ascendente durante los años sesenta y 
setenta. 1974 es el primer año en que se rebasan las 100.000 has y 1977 el último, hasta hoy, en que no se llega a 50.000. Especialmente nefastos fueron los años $1978,1985,1989$ y 1994 en que se rebasaron las 400.000 has siendo el peor de ellos 1985 con 489.476 has. El año 2000 puede calificarse de malo, aunque sin llegar a catastrófico, pues de enero a septiembre se habían producido 23.152 incendios y habían ardido 133.249 has.

Una evolución tan poco favorable no podía menos de llamar la atención de la sociedad y los medios de comunicación y despertar el interés de las autoridades e investigadores sobre sus causas, consecuencias y medidas de lucha contra ellos.

Cabe señalar que 1985, año que por ahora ostenta el primer puesto en hectáreas quemadas, coincide en el plano político en España con el periodo de transferencia de competencias sobre la gestión de los montes a las Comunidades Autónomas, lo que puede transitoriamente haber restado eficacia a la lucha contra el fuego por los inevitables desajustes que se pueden produciren todo cambio administrativo, aunque ICONA (Instituto para la Conservación de la Naturaleza) y posteriormente su sucesor la DGCN (Dirección General de Conservación de la Naturaleza), siga ocupándose de la normalización de equipos y procedimientos, la coordinación, el apoyo con medios aéreos y los seguros (VÉLEZ, 1999ª). La entrada de España en la CEE supone desde 1986 nuevos medios económicos para mejorar la lucha contra los incendios, al tiempo que campañas publicitarias simbolizadas por el slogan "todos contra el fuego" contribuyen a la concienciación de la población. Por otra parte se crean una Comisión del Senado cuyos informes (SENADO, 1993 y 1995) al igual que los libros rojos del "Comité de lucha contra incendios forestales" (CLIF, 1997 ${ }^{\mathrm{a}}$ 1997b) constituyen una referencia bibliográfica obligada.

En el plano investigador los trabajos sobre incendios experimentan también un auge creciente y los distintos colectivos científicos, geógrafos incluidos, aportan su contribución desde el ámbito de sus respectivas competencias al conocimiento de los más variados aspectos: causas naturales y humanas de los incendios, métodos de lucha, índices de peligro, modelos de riesgo, técnicas de seguimiento mediante imágenes de satélite, efectos ecológicos y erosivos, procesos de recuperación de la vegetación, consecuencias económicas, etc.... Proyectos de investigación, reuniones científicas, números monográficos y publicaciones en general, recibirán a mediados de los años noventa un nuevo impulso como consecuencia del catastrófico verano de 1994. Algunas de estas aportaciones han sido recogidas a modo de muestra en la bibliografía.

El conocimiento de las causas y factores que contribuían al continuo incremento de la gravedad del fenómeno de los incendios forestales, así como su distribución territorial y temporal eran lógicamente temas prioritarios objeto diversas publicaciones por parte de distintos autores y que han merecido especial atención en todos los informes anuales y publicaciones del ICONA y posteriormente de la DGCN. Estos dos rasgos, por otra parte relacionados entre sí, merecen en nuestra opinión especial atención, por lo que van a ser tratados brevemente a continuación.

En lo referente a su distribución, destaca, sea cual fuere el nivel territorial que tomemos como base para un análisis, la fuerte concentración en el NW tanto por el número de incendios como por las superficies quemadas. Este hecho es coherente con lo que sucede en Portugal donde también son las regiones vecinas del centro, Beira, y norte, Tras-osMontes, las más castigadas por el fuego, de modo que a escala del conjunto de la Península Ibérica la concentración en el Noroeste es aún más marcada. En segundo lugar vienen diversas cadenas montañosas: la mitad occidental del sistema Central, las montañas orientales catalanas y valencianas, de modo menos continuo diversos sectores andaluces principalmente en Huelva y Costa del Sol. No deja de ser llamativa la escasa incidencia de los incendios en los Pirineos y también en las montañas interiores de la mitad oriental y meridional peninsular: Sistema Ibérico y sierra Morena y montañas subbéticas.

Esta distribución obliga a matizar la validez de algunas las ideas ampliamente extendidas en el conjunto de la población como son las que relacionan los incendios con la sequía y con la vegetación aciculifolia, concretamente los pinares. La percepción general de la existencia de una relación directa entre sequía e incendios se basa en la mayor frecuencia y gravedad de los incendios estivales, lo que contrasta con el hecho de que las regiones del NW peninsular se caracterizan por su elevada pluviosidad y de que su déficit de precipitación estival, aunque presente, es menos acusado que en las regiones del centro y sur peninsular. Por lo que se refiere a la vegetación forestal el noroeste es el dominio preferente de robledales hayedos y otras formaciones caducifolias. Este rasgo debe sin embargo matizarse por la gran extensión ocupada por los matorrales de sustitución, brezales y tojares, y las repoblaciones de coníferas y eucaliptos, más combustibles que las manifestaciones en buen estado de los bosques caducifolios climácicos.

Esto lleva a la consideración de que la causa de esta concentración de los fuegos en el NW no se debe a causas naturales, sino a factores antrópicos ligados al aprovechamiento tradicional y actual del territorio. El fuego ha sido tradicionalmente una "herramienta" de destrucción y/o rejuvenecimiento del matorral para facilitar el aprovechamiento ganadero tan importante en estas regiones y esto se manifiesta en 
Figura 1 - Evolución

de los incendios forestales en España (1961-2000)

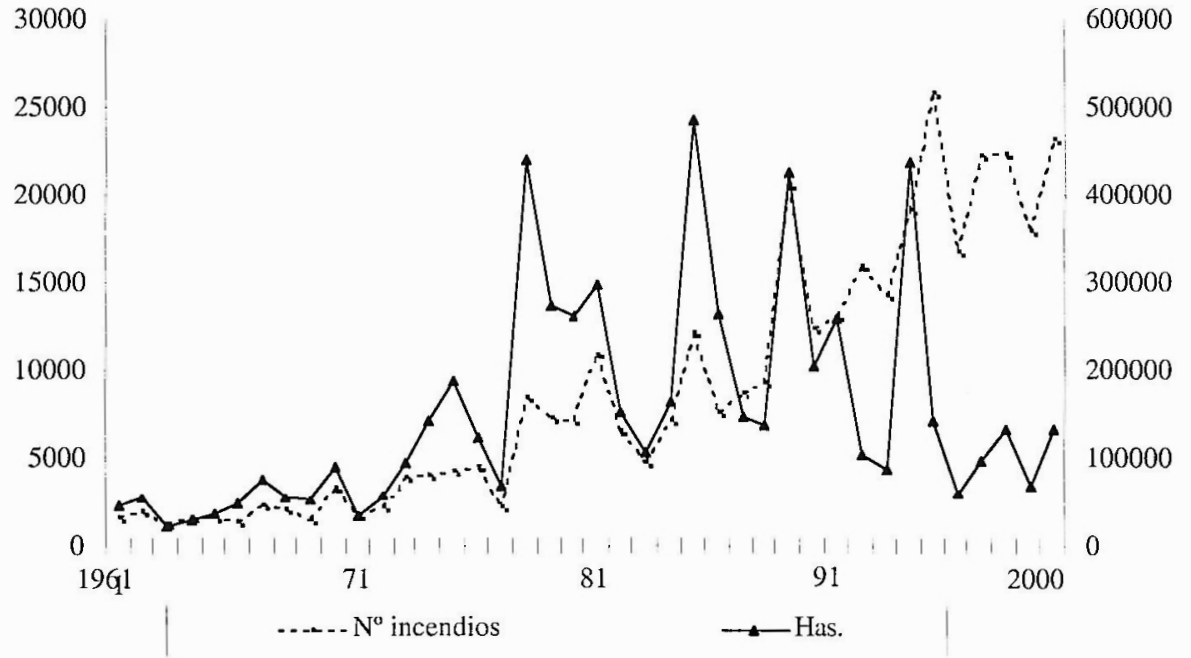

Fuente:elaborado con datos de los informes anuales de la Dirección General de Protección de la Naturaleza (DGCN) del Ministerio de Medio Ambiente.

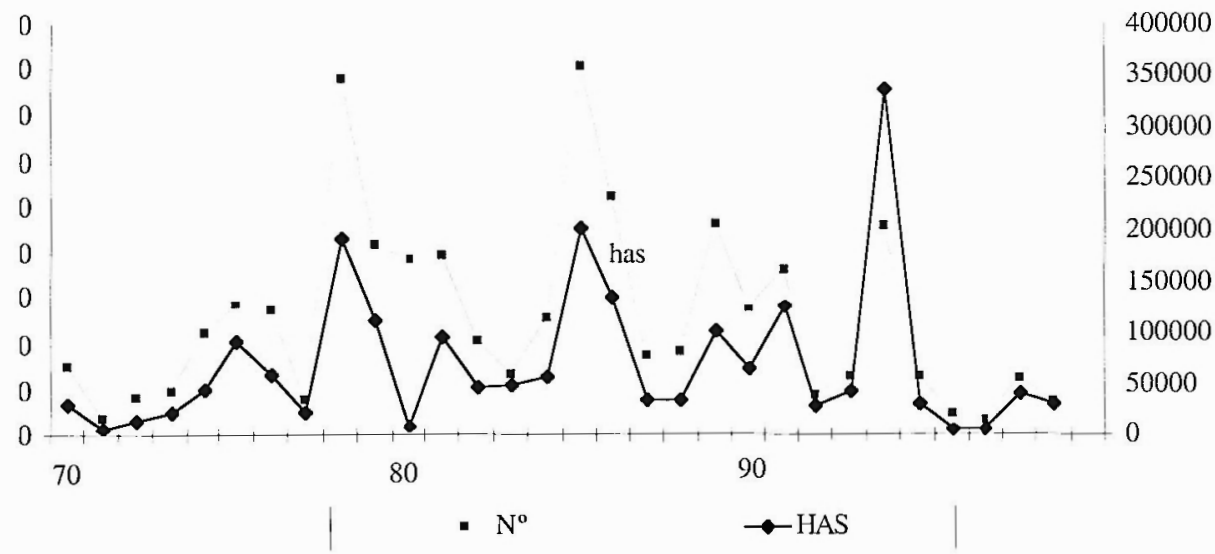

Fuente: elaborado con datos de los informes anuales de la Dirección General de Protección de la Naturaleza (DGCN) del Ministerio de Medio Ambiente.

Datos mensuales 1994-99

Figura 3 - Relación entre incendios activos y precipitación.

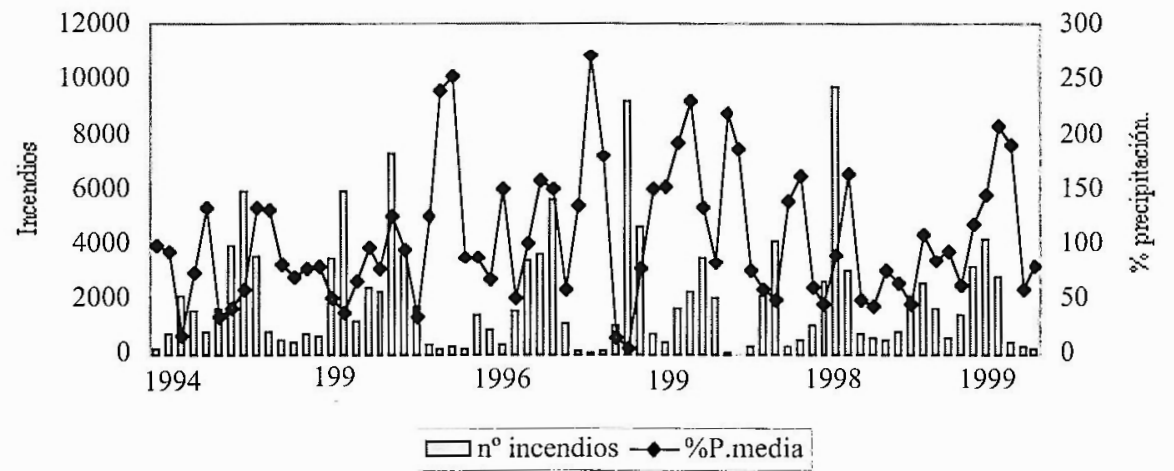

Fuentes: Elaborado con datos de los informes anuales de la Dirección General de Protección de la Naturaleza (DGCN) para los incendios y del Calendario Meteorológico de cada año del Instituto Nacional de Meteorología (INM) del Ministerio de Medio Ambiente. Se ha utilizado el \% que la precipitación de cada mes representa respecto a la precipitación mensual media para resaltar su carácter comparativamente normal, seco o lluvioso, cuya relación con los incendios activos es más expresiva. 
el diferente peso que tienen los incendios intencionados respecto al resto de España.

Según datos del periodo 1986-95 (MINISTERIO DE MEDIO AMBIENTE (1996) En el conjunto de España aproximadamente la mitad, el $49.3 \%$, de los incendios son intencionados, pero en el NW español (Galicia, Asturias, Cantabria y provincias de León y Zamora) este porcentaje se eleva hasta el $65.4 \%$, es decir casi los dos tercios. Este porcentaje baja a la cuarta parte, $25.3 \%$, en el conjunto del resto del país. En superficies quemadas la diferencia entre estos dos conjuntos regionales básicos es menor, pero todavía importante pues en el NW representan más de mitad de la superficie afectada mientras en el resto del España no llega a un tercio. En realidad la importancia de los incendios intencionados es mayor, pues es indudable que buena parte de los considerados como de causa "desconocida" son incendios provocados cuyo carácter intencionado no se ha podido probar.

El diferente comportamiento del Norte y NW respecto al resto del país se manifiesta también en el diferente ritmo estacional. La curva mensual de incendios para el conjunto del territorio español muestra un claro máximo estival y un segundo máximo menos marcado a finales de invierno y comienzo de primavera anterior al rebrote primaveral de la vegetación que dificulta la propagación del fuego en estas regiones húmedas. Este segundo máximo es más importante en las provincias norte y en algunas de ellas como en Cantabria pueden llegar a convertirse en el principal. Este máximo, aunque se debe al uso sistemático y voluntario del fuego para rejuvenecer pastos y matorrales, está influido también por la instalación de condiciones atmosféricas favorables y concretamente en el área cantábrica al viento del sur (RASILLA, 1995 y 2000).

No puede darse por concluido este breve repaso a las causas y distribución de los incendios sin aludir a una causa natural de carácter climático: el rayo. Las tormentas son un fenómeno meteorológico cuya distribución en la Península se encuentra fuertemente influida por el relieve y por un gradiente suroeste-noreste. Aunque las tormentas y los incendios provocados por el rayo puedan producirse en cualquier época del año es en verano cuando son más frecuentes tanto unas como otros y en esta estación el tiempo tormentoso en España es especialmente frecuente en montañas y tierras altas del cuadrante nororiental. La Cordillera Ibérica, los Pirineos y el Noreste de Cataluña superan los 15 días de tormenta en los meses de verano y buena parte del Sistema Central, montañas del N-NW y enclaves de la cuenca del Duero y la Mancha los 10 días. Esto se refleja en el mapa de los incendios provocados por rayo cuya frecuencia absoluta es máxima en el Sistema Ibérico meridional: Cuenca, Teruel, este de Guadalajara,
Castellón y Valencia. La importancia relativa del rayo como agente de incendios forestales es notable en Aragón y Castilla la Mancha.

Por lo que se refiere a los grandes incendios, considerando como tales a los que rebasan las 500 has, cabe destacar de su evolución su semejanza con la del total de incendios, aunque con oscilaciones más acusadas tanto en número como en superficie afectada, así como una correlación negativa relativamente buena, aunque con excepciones, con la pluviosidad.

Así en los últimos treinta años de los 8 años especialmente catastróficos, en que la superficie arrasada por grandes incendios ha rebasado las 100.000 has, 5 fueron muy secos, 1 normal y 2 húmedos. Las excepciones fueron 1978 que resultó pluvimétricamente normal y 1979 y 1989 que fueron más lluviosos que la media, lo que indica que aunque válida con carácter general no siempre hay una relación directa entre grandes incendios y sequía. Inversamente la mayoría de los años muy secos fueron malos desde el punto de vista del fuego, si bien también con excepciones, como, por ejemplo, 1999 que a pesar de ser más bien seco registró sólo 15 grandes incendios.

La distribución territorial de los grandes incendios muestra una clara concentración en el NW-W, litoral mediterráneo y en menor proporción Andalucía, por lo que sus pautas espaciales y también las causas y variaciones estacionales son semejantes a las del conjunto de los incendios. La principal causa de grandes incendios es la quema intencionada ya que este es el origen de 218 incendios de los 560 acaecidos en el periodo 1986-95 y probablemente de buena parte de los 187 calificados como de causa desconocida. Los grandes incendios provocados son especialmente importantes en Galicia, Andalucía y Castilla-León. El rayo sin embargo es la causa principal en Aragón, 10 incendios de 17 en el mismo periodo, según datos de la DGCN.

\section{Analisis del periodo 1994-2000}

Los detallados datos que los informes anuales de la DGCN incluyen de la secuencia temporal de los incendios activos cada día constituyen una fuente de gran interés para plantear con carácter general para el conjunto de España la relación entre las características del tiempo y la frecuencia de los incendios.

Los gráficos adjuntos de los años 1994-99 muestran la secuencia de los incendios activos cada día cuyas oscilaciones sugieren inmediatamente una estrecha correlación con las características del tiempo. Cada año muestra sus propias características que pasamos a describir brevemente dedicando en cada caso especial atención a algún mes o periodo concreto. 
1994: un año fatídico. 1994 ha sido uno de los años más catastróficos vividos hasta el presente tanto por el número de incendios, 19.263, como por la superficie quemada, 437635 has de las que 335.359 ardieron en los 92 incendios de más de 500 has. Estos datos le sitúan en $4^{\circ}$ lugar en número de incendios, $3^{\circ}$ en superficie quemada y por lo que se refiere a grandes incendios el 3 por número y $1^{\circ}$ por superficie. Además resultó también especialmente negativo en pérdidas de vidas humanas, con 33 víctimas en labores de extinción.

Pluviométricamente 1994 fue un año muy seco en gran parte del país principalmente en la mitad oriental donde numerosas comarcas recibieron precipitaciones inferiores a la mitad de la media. Así por ejemplo Valencia de enero a agosto recogió solo $78 \mathrm{~mm}$ de los que 52 correspondieron a abril y Teruel por su parte registró en el mismo periodo 86 mm solamente. Esta sequedad favoreció la preparación de material seco fácilmente inflamable y que ya durante la primavera, hasta principios de junio, se produjeran una decena de grandes incendios en Castellón y Cataluña. Pese a ello la primera mitad del año no fue especialmente mala ya que a mediados de junio la superficie quemada total era de 48.177 has y la frecuencia de incendios tampoco fue excesiva.

Si 1994 pasará a la historia de los incendios forestales españoles como uno de los años más catastróficos se debe especialmente al verano. Sólo en el mes de julio se produjeron 35 grandes fuegos y ardieron 240.310 has a los que hay que añadir los 29 grandes incendios con 55.829 has quemadas de agosto y los 17 grandes fuegos y 21.539 has de septiembre. Octubre fue ya un mes lluvioso, especialmente en la mitad oriental y ya no hubo más grandes incendios en lo que quedaba de año.

Las provincias más castigadas fueron Valencia con 5 incendios y 88735 has, Barcelona con 7 incendios y 39.114 has y Castellón, 3 incendios y 42.071 has. La gravedad de estos incendios estivales se vio favorecida por acusado estrés hídrico que presentaba la vegetación viva y a la abundancia de material muerto como consecuencia de la prolongada sequía. Además el mes se caracterizará por el predominio del tiempo anticiclónico cálido y muy seco con formación de un fuerte baja térmica sobre el centros sur de la península con máximas superiores a $40^{\circ} \mathrm{C}$ durante bastantes días en extensas regiones (máxima de $46^{\circ} \mathrm{C}$ en Murcia). Especialmente intensa fue la ola de calor que se presentó los del 3 al 5 de julio, asociada a vientos del oeste que explica el desarrollo de espectaculares incendios en los que en una semana radio el $40 \%$ del total quemado en todo el año. Agosto que se caracterizó también por tiempo anticiclónico con baja térmica, registrará también otras situaciones de olas de calor asociadas a vientos fuertes pero los incendios principales aunque graves fueron menos catastróficos.

1995: un año intermedio típico. 1995 puede considerarse un año intermedio típico por tanto por el número de incendios y superficies quemadas como por su distribución, que muestra un claro doble máximo en uno a fin de invierno y principios de primavera en marzo-abril y otro estival

El máximo de marzo-abril, que a pesar de tener lugar ya en meses considerados primaverales, puede calificarse de finiinvernal por presentarse fenológicamente antes de rebrote masivo de la vegetación leñosa, se debe a las quemas incontroladas de matorral en leas regiones del noroeste aprovechando un periodo seco de varias semanas en un semestre que en conjunto fue más bien lluvioso en estas regiones

El segundo va ligado a dos factores y localizaciones. Por un lado a la intensa actividad tormentosa que caracterizará a julio y agosto; por otro a las quemas incontroladas e fuegos intencionados en el NW. En julio y agosto las tormentas secas provocaron, o fueron aprovechadas para provocar, numerosos incendios en diversos lugares de la Península, destacando en el centro los de El Tiemblo en Avila y Somosierra-Rrobregordo en Madrid., ambos debidos a rayos. A finales de agosto y primeros de septiembre la proliferación de incendios intencionados en el NW alcanzo tal virulencia que se llegan a rebasar durante varios días los 500 incendios activos, lo que llevó a tener que recurrir al ejército para intentar controlarlos. El día 5 un cambio de tiempo con Iluvias generalizadas alivió la situación.

Pluviométricamente fue sin embargo bastante seco en conjunto y en realidad más seco funcionalmente de lo que pueden indicar las medias por "su anárquico comportamiento: se pasaba de la nada (dura sequía) al todo (torrenciales aguaceros)" (CALENDARIO METEOROLOGICO 1996). Invierno y primavera fueron en conjunto secos en gran parte de España, sobre todo en el centro y este. Es destacable que después de un comienzo de primavera suave y moderadamente seco, mayo fue muy seco y con heladas tardías, al que seguirá un verano tormentoso y caluroso en el que torrenciales aguaceros, que aparte de su efecto destructor apenas alivian globalmente la sequía que se prolongara hasta que las abundantes lluvias de noviembre y diciembre den paso a un periodo lluvioso.

1996: un año lluvioso con pocos incendios. 1996 será el más lluvioso de los últimos treinta, ya sus $893 \mathrm{~mm}$ para el conjunto de España superan en $234 \mathrm{~mm}$ la media del periodo 1961-90. Debido a ello serás un año favorable sin apenas grandes fuegos. En el primer semestre no hubo ningún fuego de 


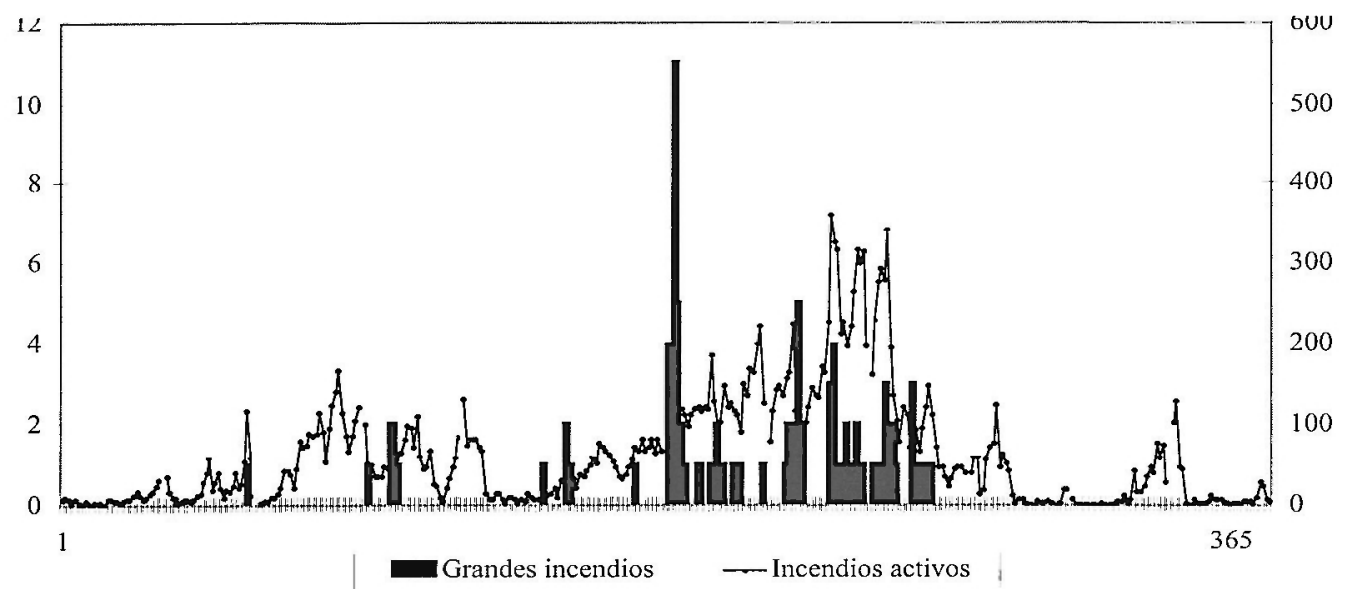

Figura 4 - Datos diarios de incendios activos y grandes incendios activos en 1994.

Fuente: elaborado con datos de los informes anuales de la Dirección General de Protección de la Naturaleza (DGCN) del Ministerio de Medio Ambiente. Se ha dejado un espacio de dato en blanco entre mes y mes para facilitar la lectura del gráfico.
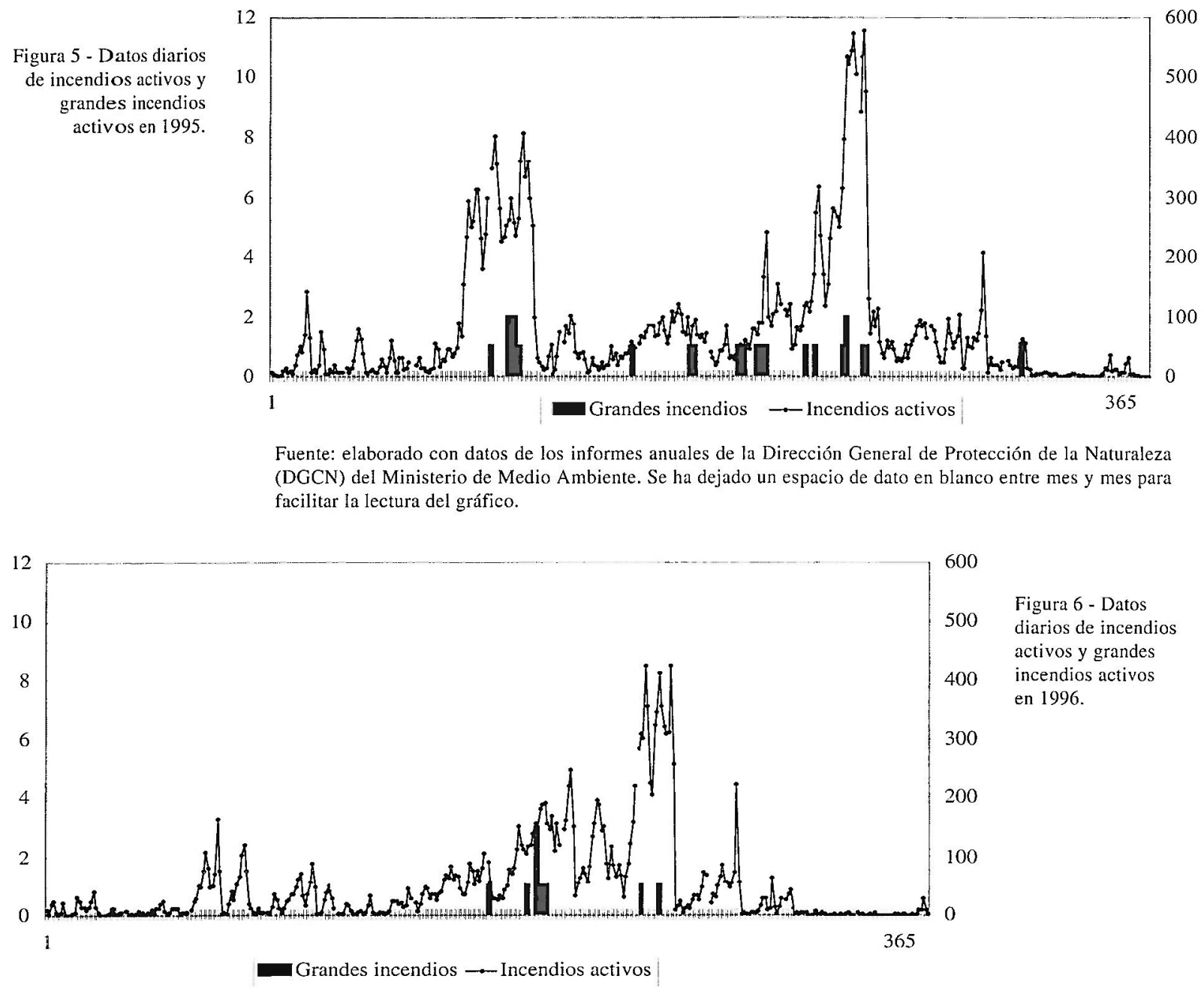

Figura 6 - Datos diarios de incendios activos y grandes incendios activos en 1996.

Fuente: elaborado con datos de los informes anuales de la Dirección General de Protección de la Naturaleza (DGCN) del Ministerio de Medio Ambiente. Se ha dejado un espacio de dato en blanco entre mes y mes para facilitar la lectura del gráfico. 
grandes proporciones. Julio con 8 y septiembre con 2 se repartieron los 10 grandes incendios y 6910 has, de los que 7 se localizaron en León-Zamora

1997: una distribución mensual atípica: Con 840 mm de precipitación media 1997 debe ser considerado también como un año muy lluvioso, aunque con una distribución estacional atípica que tendrá su reflejo en los incendios forestales y su marcha anual. Como suele corresponder a los años lluviosos todos los datos de incendios son favorables y concretamente el la cifra total de grande incendios es la más baja desde 1970, primer año del que disponemos de datos.

Lo más llamativo de 1997 es que tanto el número de incendios activos cada día como el de grandes incendios presenta un único máximo tardiinvernal, debido a la coincidencia en el NW de las habituales quemas de matorral y pastos con una prolongada sequía que afecto a toda Europa atlántica de febrero a abril. En estos meses se produjeron seis de los siete grandes incendios del año, todos ellos en el noroeste:

1998: otro año intermedio típico. Al contrario de los precedentes 1998 será un año seco, con el resultado de un claro empeoramiento en lo referente a incendios forestales cuya frecuencia, magnitud y distribución se asemejan a las de 1995 pudiendo calificarse como el de otro año intermedio, es decir moderadamente malo, con típico doble máximo en frecuencia e intensidad de los incendios.

1998 comienza siendo lluvioso, pues en enero contiuarán todavía las abundantes precipitaciones del año anterior, pero febrero y marzo serán muy secos y con temperaturas cálidas para la época. Con frecuentes advecciones de $\mathrm{S}$ o $\mathrm{SW}$, que se reflejan en la marcha diaria del número de incendios activos y la aparición de los primeros grandes incendios, que como es habitual en estos casos tendrán una marcada concentración en el $\mathrm{N}$ y NW.

Del 10 al 20 de febrero una advección del sur mantiene la cifra diaria de incendios activos por encima del centenar llegando a 299 el día 20 , fecha en que se produce el primer gran incendio en Lezo (Guipúzcoa).

Marzo comienza con una advección del sur y abundantes fuegos en Galicia. El día 3 es especialmente negro con 511 incendios activos y se producen dos grandes incendios, uno en Asturias y otro en Galicia. En la última década una nueva situación de flujo del sur vuelve a hacer aumentar los incendios y tiene lugar el cuarto gran incendio en la comarca leonesa del Bierzo.

La primavera será lluviosa con reflejo en un reducido número de fuegos y ausencia de grandes incendios en abril mayo y junio en la península. Esta primavera favorable para el desarrollo de la vegetación herbácea proporcionará sin embargo abundante combustible para los incendios de un verano que se caracterizara por la escasez de precipitaciones y frecuentes e intensas olas de calor. En julio habrá 4 grandes fuegos uno de ellos en Aguilar de Segarra (Barcelona), especialmente grave con 12.510 has de superficie forestal y 5.164 has no forestales, pero el mes peor será agosto con 10 grandes fuegos en el NW y otro en Cáceres. En los meses siguientes todavía se producirán en el León y Zamora otros 3 grandes fuegos, a pesar de que en conjunto el último cuatrimestre del año se caracteriza por ser relativamente.

Rasgo llamativo de este año es por otra parte el haber sido especialmente negativo para Canarias al haberse producido en las islas tres grandes fuegos uno en abril otro en agosto y el último en noviembre con un total de 2.775 has.

1999: un año con máximos poco marcados. A pesar de que las lluvias abundantes de septiembre-octubre hacen 1999 fue un año de precipitaciones normales al final del año, desde el punto de vista de los incendios forestales debe considerarse un año más bien seco ya que con tal se comportó en la mayoría de los meses en la mayor parte del territorio.

El invierno frío y más bien seco, primavera moderada en lluvias y variable, con predominio de los días fríos y soleados en marzo, importantes heladas tardías en abril y un mayo pródigo en tormentas y chubascos que provocaron numerosos incendios por rayo y que solo a finales presento se presentó caluroso. Así los primeros meses presentan varios picos aislados y no muy marcados en frecuencia de incendios con 4 de más de 500 has: tres en Zamora (uno en febrero y dos en marzo) y otro en abril en Castellón.

A esta primavera fresca y entre seca y lluviosa según regiones siguió un verano sin grandes calores continuados y con frecuencia nuboso y tormentoso por lo que ni el numero de incendios activos ni el de grandes fuegos alcanzan valores elevados; sólo 10 días superan los 200 incendios activos y el número de grandes incendios estivales entre el 29 de junio y el 1 de septiembre es de 11. El ciclo se cierra en octubre con el incendio de Artá en Mallorca.

2000: un final de milenio poco favorable. Los datos disponibles, menos completos y limitados al periodo enero-septiembre, permiten calificar al año 2000 como más bien malo. El número de incendios ha sido muy elevado llegando en estos nueve meses a 23.252, la superficie quemada a 133.249 has y la cifra de grandes incendios 19. En estos datos poco favorables ha influido el que haya sido un año bastante seco. El noroeste se lleva la peor parte pues concentra 
Figura 7 - Datos diarios de incendios activos $y$ grandes incendios activos en 1997.

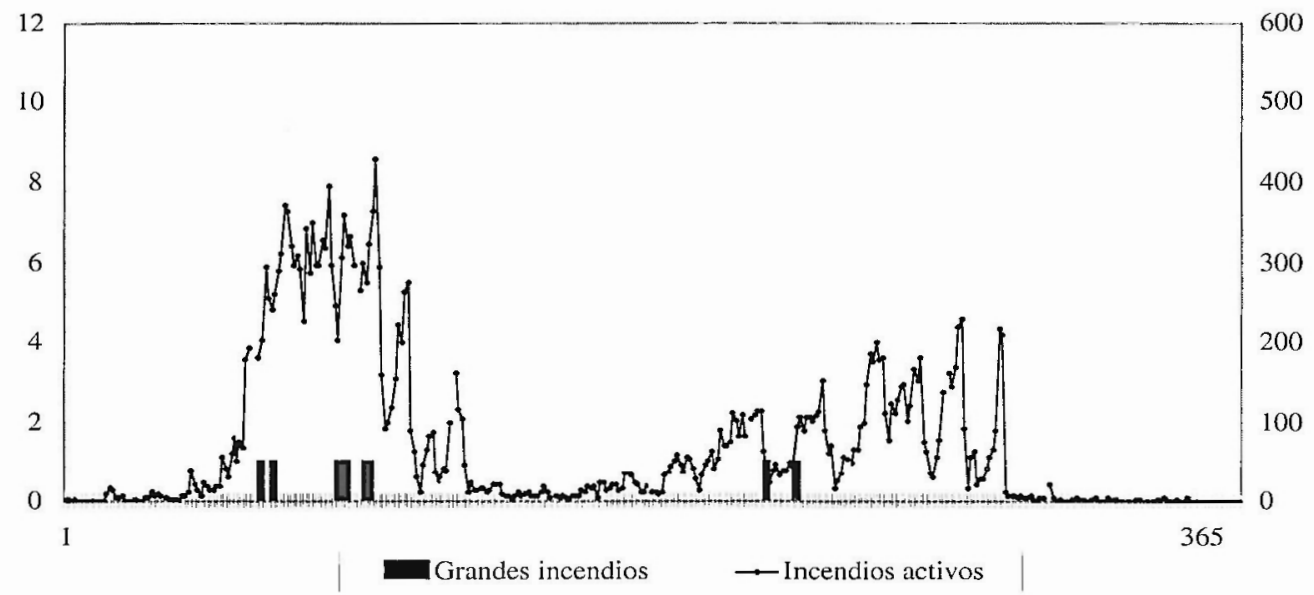

Fuente: elaborado con datos de los informes anuales de la Dirección General de Protección de la Naturaleza (DGCN) del Ministerio de Medio Ambiente. Se ha dejado un espacio de dato en blanco entre mes y mes para facilitar la lectura del gráfico.

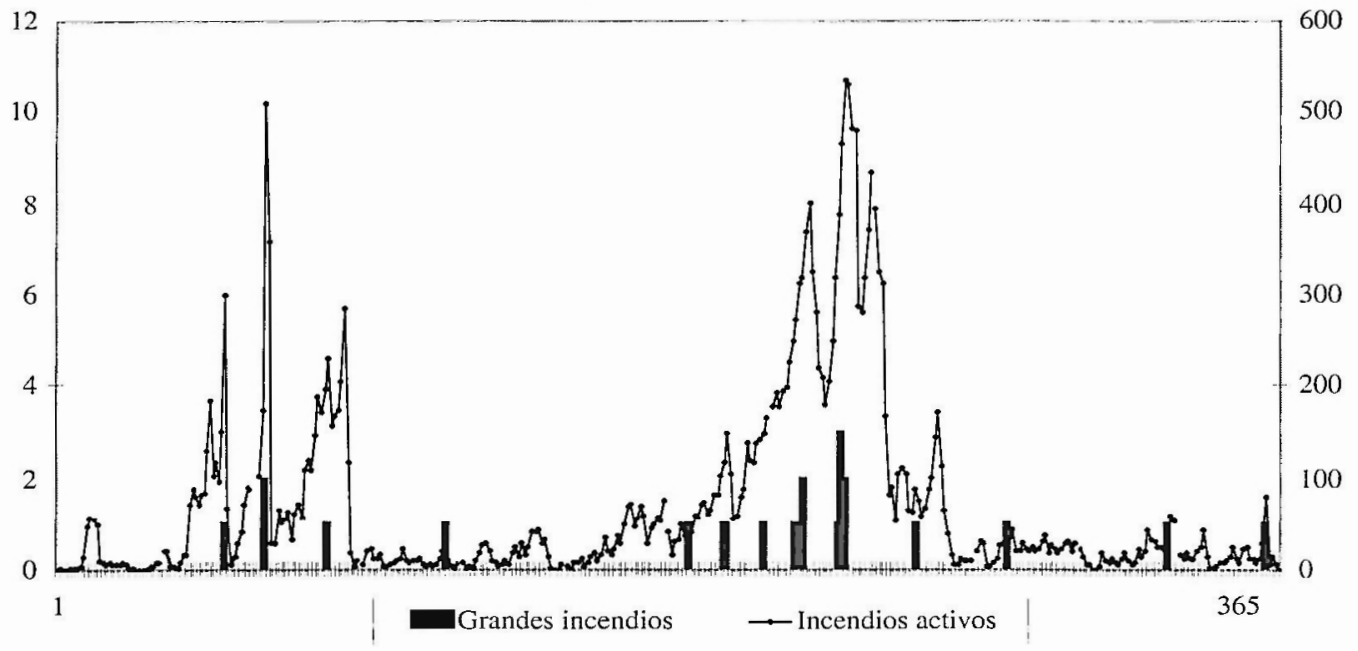

Figura 8 - Datos diarios de incendios activos y grandes incendios activos en 1998 .

Fuente: elaborado con datos de los informes anuales de la Dirección General de Protección de la Naturaleza (DGCN) del Min isterio de Medio Ambiente. Se ha dejado un espacio de dato en blanco entre mes y mes para facilitar la lectura del gráfico.

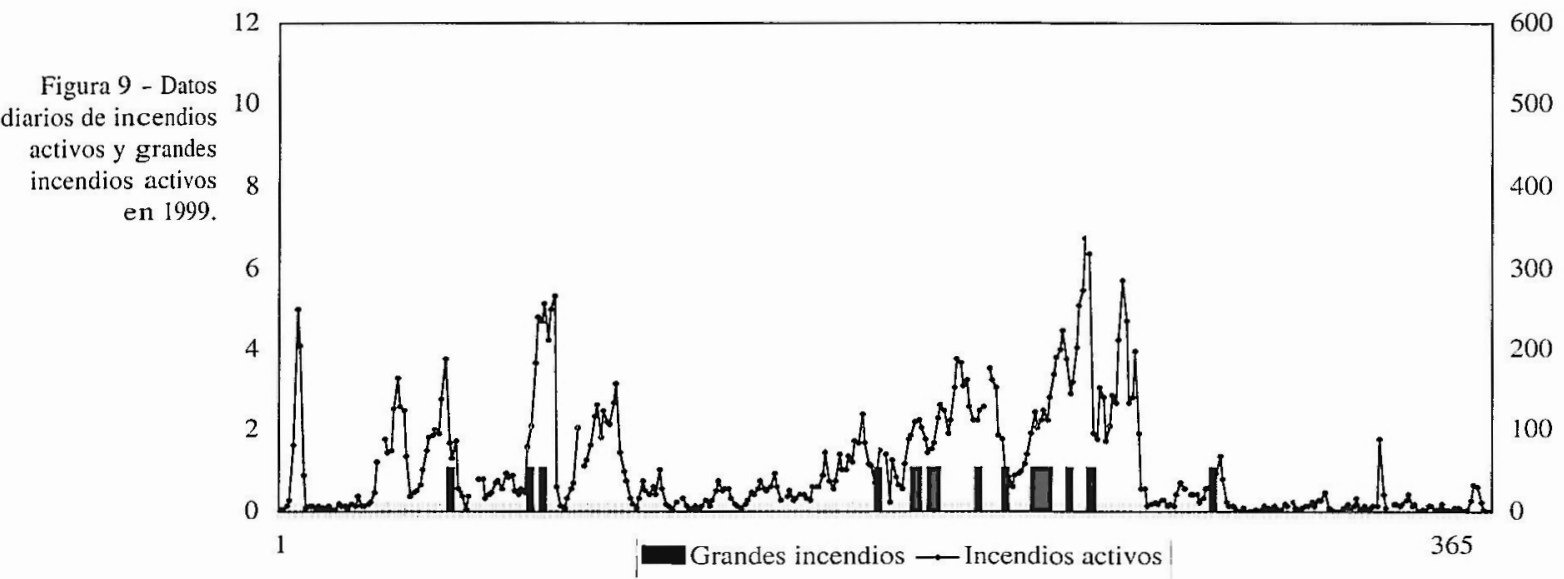

Fuente: elaborado con datos de los informes anuales de la Dirección General de Protección de la Naturaleza (DGCN) del Ministerio de Medio Ambiente. Se ha dejado un espacio de dato en blanco entre mes y mes para facilitar la lectura del gráfico. 
el $70 \%$ del total de los incendios, el $56 \%$ de la superficie quemada, aunque solo 4 de los 19 grandes incendios se localizaron en él.

El año comienza con una prolongada sequía que dura hasta mediados de marzo en gran parte del país con numerosos incendios, en su mayoría pequeños, en eI NW, Centro y Este. El 1 de marzo tiene lugar el primer gran incendio en L'Albiol (Tarragona). Tras una primavera lluviosa que abarca la última decena de marzo y los meses de abril y mayo, el verano es largo seco y calurosos ya desde junio. Las lluvias primaverales permitieron un abundante desarrollo de la vegetación herbácea que los fuertes calores y sequedad convertirán en un combustible presto a facilitar la propagación de los incendios cuya gravedad irá aumentando a medida que hacia la segunda mitad del verano. Así mientras junio sólo registra un gran incendio en Zamora y julio otro en Canarias, en agosto se producirán 11 y en septiembre otros 5 fuegos.

La influencia de las situaciones meteorológicas en estos grandes incendios es clara. El incendio de la isla de La Palma, iniciado el 29 de julio y que afecto 3.912 has forestales y 1754 has agrícolas, coincide con vientos muy cálidos y secos debidos a una invasión de aire sahariano. Agosto, de seco a muy seco en gran parte del país, se caracterizó por frecuentes tormentas secas, que independientemente de que se debieran a un rayo o fueran intencionados, recibían el impulso de fuertes vientos y remolinos ascendentes. Un buen ejemplo es que tuvo lugar entre el 10 y el 15 de septiembre en Pedrobernardo; en la abulense sierra de Gredos, que tuvimos ocasión de vivir personalmente, cuyo carácter intencionado está demostrado y que coincidió con un tiempo de estas características, arrasando más de 3.000 has.

\section{Conclusiones}

En el estado actual del conocimiento de los incendios forestales en España los estudios y realizados y los datos disponibles sobre su evolución, su distribución, sus causas y factores, los medios de lucha, etc... permiten señalar como rasgos que, en nuestra opinión, resultan especialmente significativos e importantes los siguientes:

Los incendios forestales han presentado durante los años sesenta, setenta y ochenta una clara tendencia ascendente que debe atribuirse principalmente a los cambios en el uso del territorio acaecidos en el mundo rural. La decadencia o desaparición de formas tradicionales de aprovechamiento del leñas y pastos, ha contribuido a proporcionar más combustible y dar al fuego mayor virulencia y capacidad de propagación, dificultando su control. El abandono del cultivo en tierras marginales que van siendo invadidas por una vegetación con frecuencia fácilmente incendiable y hasta cierto punto las repoblaciones con coníferas o eucaliptos, cuyo sotobosque heliófilo es altamente pirófílo, han debido constituir también un factor que ha favorecido la mayor frecuencia y gravedad de los incendios. Aunque la quema intencionada sea la causa principal de los incendios y buena parte de los calificados como de "causas desconocida" sean también provocados, no cabe pensar en un aumento generalizado de la intencionalidad en este aumento al menos los datos disponibles no permiten apreciar en este aspecto cambios suficientemente estables y significativos.

La variabilidad interanual, estacional y diaria de muestra una influencia notable de las características pluviométricas del año y de los tipos de tiempo en la frecuencia y gravedad de los incendios. El análisis que hemos presentado de la evolución del numero de incendios activos cada día y de los grandes incendios para el periodo $1994-2000$ y sus relaciones con las características del tiempo presente y del de los meses precedentes lo pone claramente de manifiesto. La frecuencia de incendios activos muestra una influencia muy directa con el tiempo presente. Los picos y periodos de abundantes incendios de la curva diaria se suelen corresponder con situaciones anticiclónicas o advecciones cálidas y/o secas y sus caídas bruscas el cambio a una situación de lluvia. La relación con los grandes incendios es más laxa. Su número relativamente reducido, sobre todo en años lluviosos, les hace depender principalmente de otros factores como relieve, vientos locales, accesibilidad, abundancia e inflamabilidad del combustible y otros que pueden condicionar su propagación y las labores de extinción. Con todo puede establecerse una relación con periodos secos, tiempo anticiclónico y/o vientos desecantes, aunque la presencia de estas condiciones atmosféricas no tenga por qué ir acompañada del desencadenamiento de un gran incendio.

La tendencia creciente que los incendios forestales presentaban en los años setenta y ochenta parece que debe darse por terminada y haber dado paso a una nueva fase caracterizada por un ligero retroceso, o al menos un estancamiento. Desde que en 1974 se rebasaron por primera vez 100.000 has quemadas y hasta 1992 sólo en 1978 se había conseguido bajar de esa superficie. Sin embargo en los últimos años se ha logrado en 4 ocasiones: 1993, 1996, 1997 y 1999. Es cierto que de estos cuatro años dos de ellos, 1996 y 1997, han sido especialmente lluviosos, pero los otros dos han registrado precipitaciones inferiores a la media y pueden calificarse de secos. Indudablemente esta cambio hay que atribuirlo a una mayor eficacia en la lucha contra el fuego, más y mejores medios, mejoras en prevención y vigilancia, mayor rapidez y eficacia en la información, mejor conocimiento del 
funcionamiento del fuego información meteorológica más precisa para valorar el riesgo de incendio, mayor experiencia y mejor capacitación y organización del personal encargado de las distintas labores, etc... El estudiode las relaciones entre situaciones sinópticas y tipos de tiempo y los incendios forestales a través de un mejor conocimiento de los componentes del riesgo de incendio que dependen de ellos puede contribuir a su prevención y a un uso coordinado de medios en busca de la máxima eficacia en la lucha contra la plaga de los incendios forestales.

\section{Bibliografia}

ALVAREZ CALVENTE, M. (1999) - "Grandes incendios en Malaga”. En VÉLEZ, R., [coord.] (1999). La defensa contra incendios forestales. Fundamentos y experiencias. Mc Graw Hill.

ARTECHE, J.C. (1993) - "El Sur". Boletín Climatológico de Cantabria. Centro Meteorológico territorial de Cantabria, p. 1-3.

CASTELLNOU, M. (1998) - "Pautas para la ordenación del territorio para la lucha contra los grandes incendios forestales". III Forum de Política Forestal, Centre Forestal Tecnològic de Catalunya. Univ. Lleida. Vol. 6:267-273.

CHUVIECO,E., MARTIN, M"P. \&SALAS, F.J.(1998)-“Geografía e incendios forestales". Serie Geográfica, 7, p. 11-17.

COMITÉ DE LUCHA CONTRA INCENDIOS FORESTALES (CLIF) (1997) - Libro rojo de la prevención de incendios forestales. ETS Ingenieros de Montes.

COMITÉ DE LUCHA CONTRA INCENDIUOS FORESTALES (CLIF) (1997) - Libro rojo de la coordinación contra los incendios forestales. ETS Ingenieros de Montes.

CURRAS CAYON, R., GUARA REQUENA, M., \& LAGUNA, E. (1987)-"El pirofitismo de la vegetación mediterránea ibérica, sus consecuencias sobre la ordenación forestal y algunas medidas preventivas". Documentos del Seminario sobre métodos y equipos para la prevención de incendios forestales, Valencia.

CURRAS CAYON, R., GUARA REQUENA, M., \& LAGUNA, E. (1987)-"Relación entre la intensidad del viento y la incidencia de grandes incendios en el Levante español". Documentos del Seminario sobre métodos y equipos para la prevención de incendios forestales. Valencia.

CURRAS CAYON, R., LAGUNA, E. \& GUARA REQUENA, M. (1987) - "Los grandes incendios por comarcas en el Levante español: relaciones entre el incendio y algunos factores socioeconómicos". Documentos del Seminario sobre métodos yequiposparala prevención de incendios forestales, Valencia, p. $157-167$.
CURRÁS, R. (1999) - "El gran incendiode Buñol (Valencia), 1991. En VÉLEZ, R. [coord] (1999), La defensa contra incendiosforestales. Fundamentos y experiencias, Mc Graw Hill, ap. 21108.

DOCTOR CABRERA, A. (1991) - Los incendios forestales en la provincia de Córdoba. Junta de Andalucía. Publicaciones de la Universidad de Córdoba, Estudios de Geografía, $n^{\circ} 2$.

ELVIRA MARTIN, M. (1989) - "Inflamabilidad y energía en las especies de sotobosque". INIA. Monografías $n^{\circ} 68$.

GENERALITATVALENCIANA (1988)-Los incendiosforestales en la Comunidad valenciana. Generalitat Valenciana. Conselleria d'Agricultura i Pesca.

HOLGUÍN, M.A. (1999) - "El gran incendio de Tabuyo (León), 1998". En VÉLEZ, R., [coord] (1999), La defensa contra incendios forestales. Fundamentos y experiencias, Mc Graw Hill, ap. 21119.

INM(1995)-Apuntes de la Campaña de Apoyo Meteorológicopara la Prevención y la Lucha contra Incendios Forestales. Madrid.

INM(1996)-Apuntes de la Campaña de Apoyo Meteorológico para la Prevención yla Lucha contra Incendios Forestales. Madrid.

INM. (1997) - Calendario Meteorológico 2000. Ministerio de Medio Ambiente, Instituto Nacional de Meteorología.

INM. (1998)-Calendario Meteorológico 2001. Ministerio de Medio Ambiente, Instituto Nacional de Meteorología.

INM. (1999)-Calendario Meteorológico 2001. Ministerio de Medio Ambiente, Instituto Nacional de Meteorología.

INM. (2000)-Calendario Meteorológico 2000. Ministerio de Medio Ambiente, Instituto Nacional de Meteorología.

INM. (2001) - Calendario Meteorológico 2001. Ministerio de Medio Ambiente, Instituto Nacional de Meteorología.

MARTIN, Ma P., CHUVIECO, E., e AGUADO, I. (1998) - "La incidencia de los incendios forestales en España". Serie Geográfica, 7, p. 23-36.

MINISTERIO DE MEDIO AMBIENTE (1995) - Los incendios forestales en España durante 1994. Avance informativo. Ministerio de Medio Ambiente. Dirección General de Conservación de la Naturaleza.

MINISTERIO DE MEDIO AMBIENTE (1996) - Los incendios forestales en España durante el decenio 1986-1995. Resumen informativo. Ministerio de Medio Ambiente. Dirección General de Conservación de la Naturaleza.

MINISTERIO DE MEDIO AMBIENTE (1996) - Los incendios forestales en España durante 1995. Avance informativo. Ministerio de Medio Ambiente. Dirección General de Conservación de la Naturaleza.

MINISTERIO DE MEDIO AMBIENTE (1997) - Los incendios forestales en España durante 1996. Avance informatio. Ministerio de Medio Ambiente. Dirección General de Conservación de la Naturaleza. 
MINISTERIO DE MEDIO AMBIENTE (1998) - Los incendios forestales en España durante 1997. Avance informativo. Ministerio de Medio Ambiente. Dirección General de Conservación de la Naturaleza.

MINISTERIO DE MEDIO AMBIENTE (1999) - Los incendios forestales ent España durante 1998. Avance informativo. Ministerio de Medio Ambiente. Dirección General de Conservación de la Naturaleza.

MINISTERIO DE MEDIO AMBIENTE (2000) - Los incendios forestales en España durante 1999. Avance informativo. Ministerio de Medio Ambiente. Dirección General de Conservación de la Naturaleza.

MINISTERIO DEAGRICULTURA, PESCA Y ALIMENTACION (1986) - Distribución temporal del peligro de incendios forestales.

MORENO, J.M., (1999) - La respuesta de las piantas al fuego. En VÉLEZ, R., [coord.] (1999), La defensa contra incendios forestales. Fundamentos y experiencias. Mc Graw Hill.

MORENO, J.L., FERNANDEZ, F., VALLEJO, R., CARBO, E., BOCIO, I., VALLE, F.,

RETANA, X. e BUSQUETS, I. (1997) - Regeneración de la vegetación en zonas quemadas por los grandes incendios de 1994. I Seminario Nacional. Estado de la investigación y el desarrolloen protección contra incendios forestales en España, Santiago, p. 177-190.

PARDO PASCUAL, J.E., RUIZ,L.A., PORRES DE HAZA,M.J., FERNANDEZ SARRIA,A. \& URBANO,F. (1999) "Caracterización entre la insolación y la regeneración vegetal tras incendios forestales en ámbitos mediterráneos". Actas XVICongreso de Geógrafos Españoles, pp. 221-232. [Málaga].

PEREZ CABELLO, F. (1999) - "Dinámica del paisaje vegetal tras el fuego del quejigal y pinar albar prepirenaico". Actas XVI Congreso de Geógrafos Españoles, pp,243-252. [Málaga].

PURROY, I. (1993) - "Incendios forestales de invierno en la zona Cantábrica". Navarra Agraria, 80, p. 62-64.
RASILLA ALVAREZ, D.F. (1995) - "Factores determinantes de los incendios en Cantabria. Una aproximación al impacto de los vientos del Sur". Actas de la II Reunión del Grupo de Climatología. Riesgo Climático en España. Instituto Pirenaico de Ecología/CSIC, p. 254-260.

RASILLA ALVAREZ, D.F. (2000) - "Viento del sur y efecto Föhn en la Cordillera Cantábrica”. Madrid CEDEX, 302 págs.

REBELO, F. (1977) - "Condições de tempo favoráveis a ocorrência de incêndios florestais". Biblos, 56.

RUIZ DEL CASTILLO, J. (1999) - "El fuego factor ecológico". En VÉLEZ, R., [coord.] (1999). La defensa contra incendios forestales. Fundamentos y experiencias. Mc Graw Hill.

SENADO (1993) - Informe de la ponencia sobre incendios forestales. Secretaria General del Senado. Servicio de Publicaciones. Madrid, 87 págs.

SENADO,(1995)-Informe de laponencia sobre incendios forestales. Secretaria General del Senado. Servicio de Publicaciones. Madrid, 51 págs.

VÉLEZ, R., (1999) - "Perspectiva histórica de los incendios forestales en España. En VÉLEZ, R., [coord.] (1999). La defensa contra incendios forestales. Fundanentos y experiencias. Mc Graw Hill, p. 3.15-3.30.

VÉLEZ, R. (1998) - "Valoración del daño ambiental de Ios incendios forestales". III Forum de Politica Forestal, Centre Forestal Tecnològic de Catalalunya. Univ. Lleida. Vol. 6:207-220.

VÉLEZ, R. [coord.] (1999)-Ladefensa contra incendios forestales. Fundamentos y experiencias. Mc Graw Hill.

VILLAESCUSA, R. \& MARTINEZ,E. (1984). Comportamiento del fuego en los incendios. Factores topográficos. CSDIF, ICONA.

ZARRAGA MORENO, J.L. (1988). Los incendios forestales y las actitudes de la población de las comarcas afectadas. Junta de Andalucía. Servicio de Estudios e Informes del IARA. 
Cuadro 1

Evolución de los incendios forestales en España (1961-2000).

\begin{tabular}{|c|c|c|c|c|c|c|c|}
\hline \multirow{2}{*}{ AÑO } & \multicolumn{3}{|c|}{ Total incendios } & \multicolumn{3}{|c|}{ Grandes incendios } & \multirow{2}{*}{ Tipo de año } \\
\hline & $\mathrm{N}^{0}$ & Has. & Has/fuego & $\mathrm{N}^{\circ}$ & Has. & Has/fuego & \\
\hline 1961 & 1680 & 46251 & 27,5 & & & & húmedo \\
\hline 1962 & 2022 & 55482 & 27,4 & & & & húmedo \\
\hline 1963 & 1302 & 22679 & 17,4 & & & & muy húmedo \\
\hline 1964 & 1645 & 31398 & 19,1 & & & & muy seco \\
\hline 1965 & 1686 & 38018 & 22,5 & & & & normal \\
\hline 1966 & 1443 & 49354 & 34,2 & & & & húmedo \\
\hline 1967 & 2299 & 76575 & 33,3 & & & & muy seco \\
\hline 1968 & 2115 & 56497 & 26,7 & & & & seco \\
\hline 1969 & $15 \overline{58}$ & 53739 & 34,5 & & & & muy húmedo \\
\hline 1970 & 3450 & 90547 & 26,2 & 31 & 32406 & 1045,35 & muy seco \\
\hline 1971 & 1718 & 35044 & 20,4 & 8 & 7138 & 892,25 & húmedo \\
\hline 1972 & 2194 & 57753 & 26,3 & 17 & 15299 & 899,941 & húmedo \\
\hline 1973 & 3932 & 96989 & 24,7 & 20 & 24973 & 1248,65 & muy seco \\
\hline 1974 & 4088 & 142115 & 34,8 & 45 & 46773 & 1039,4 & muy seco \\
\hline 1975 & 4340 & 188595 & 43,5 & 58 & 92613 & 1596,78 & seco \\
\hline 1976 & 4577 & 123577 & 27,0 & 55 & 59807 & 1087,4 & normal \\
\hline 1977 & 2221 & 70749 & 31,9 & 16 & 24106 & $150 \overline{06,63}$ & húmedo \\
\hline 1978 & 8471 & 439526 & 51,9 & 156 & 191142 & 1225,27 & normal \\
\hline 1979 & 7222 & 273567 & 37,9 & 84 & 111009 & 1321,54 & húmedo \\
\hline 1980 & 7190 & 263017 & 0,0 & 77 & 106600 & 1384,42 & muy seco \\
\hline 1981 & 10878 & 298288 & 14,1 & 79 & 95775 & 1212,34 & muy seco \\
\hline 1982 & 6545 & 152903 & 16,5 & 41 & 48712 & 1188,1 & muy seco \\
\hline 1983 & 4791 & 108100 & 34,5 & 27 & 50183 & $185 \overline{8,63}$ & muy seco \\
\hline 1984 & 7203 & 165119 & 67,3 & 51 & 57181 & 1121,2 & normal \\
\hline 1985 & 12238 & 484476 & 39,6 & 161 & 201703 & 1252,81 & muy seco \\
\hline 1986 & 7570 & 264887 & 35,0 & 104 & 135756 & 1305,35 & muy seco \\
\hline 1987 & 8679 & 146662 & 16,9 & 35 & 36563 & 1044,66 & normal \\
\hline 1988 & 9247 & 137734 & 14,9 & 37 & 35205 & 951,486 & seco \\
\hline 1989 & 20593 & 426568 & 20,7 & 93 & 101611 & 1092,59 & húmedo \\
\hline 1990 & 11609 & 202825 & 17,5 & 56 & 66183,8 & 1181,85 & muy seco \\
\hline 1991 & 11735 & 259418 & 22,1 & 73 & 126179 & 1728,48 & muy seco \\
\hline 1992 & 15380 & 104592 & 6,8 & 18 & 30918,6 & 1717,7 & seco \\
\hline 1993 & 13692 & 89267 & 6,5 & 26 & 44037,3 & 1693,74 & seco \\
\hline 1994 & 17597 & 437635 & 24,9 & 92 & 335359 & 3645,21 & muy seco \\
\hline 1995 & 23300 & 143484 & 6,2 & 26 & 31399,8 & 1207,68 & seco \\
\hline 1996 & 15319 & 59825 & 3,9 & 10 & 6960 & 696 & muy húmedo \\
\hline 1997 & 20321 & 98503 & 4,8 & 7 & 5309,4 & 758,486 & muy húmedo \\
\hline 1998 & 20367 & 132813 & 6,5 & 25 & 41761,6 & 1670,46 & muy seco \\
\hline 1999 & 16420 & 78545 & 4,8 & 15 & 32120 & 2141,33 & seco \\
\hline 2000 & 23252 & 133249 & 5,7 & 19 & {$[-]$} & {$[-]$} & {$[-]$} \\
\hline
\end{tabular}


Cuadro 2

Datos mensuales del periodo 1994-1999.

\begin{tabular}{|c|c|c|c|c|c|c|}
\hline \multirow{2}{*}{ Mes } & \multirow{2}{*}{ Año } & \multicolumn{2}{|c|}{ Total incendios } & \multicolumn{2}{|c|}{ Incendios $>500$ has } & \multirow{2}{*}{ \%P.media } \\
\hline & & $N^{\circ}$ activos & Has & $\mathrm{N}^{\circ}$ & has & \\
\hline 1 & 1994 & 233 & 1426 & 0 & $\bar{O}$ & 98 \\
\hline 2 & 1994 & 743 & 5622 & 1 & 512 & 94 \\
\hline 3 & 1994 & 2117 & 7133 & 0 & 0 & 16 \\
\hline 4 & 1994 & 1596 & 22090 & 6 & 15937 & 72 \\
\hline 5 & 1994 & 840 & 4852 & 1 & 2350 & $13 \overline{3}$ \\
\hline 6 & 1994 & 1659 & 18312 & 4 & 10531 & 33 \\
\hline 7 & 1994 & 3915 & 254603 & 35 & 240310 & 41 \\
\hline 8 & 1994 & 5923 & 84194 & 29 & 55829 & 57 \\
\hline 9 & 1904 & 3545 & 35731 & 16 & 25539 & 132 \\
\hline 10 & 1994 & 811 & 2077 & 0 & () & 130 \\
\hline 11 & 1094 & 506 & 1494 & 0 & 0 & 81 \\
\hline 12 & 1994 & 478 & 1067 & 0 & 0 & 69) \\
\hline$\overline{A N O}$ & 1994 & 22366 & 438601 & $\overline{92}$ & 351008 & 84 \\
\hline 1 & 1995 & 712 & 3268 & $\overline{0}$ & 0 & 76 \\
\hline 2 & 1995 & 658 & 3057 & 0 & 0 & 78 \\
\hline 3 & 1995 & 3429 & 17950 & o & 0 & 50 \\
\hline 4 & 1995 & 5852 & 35652 & 7 & 5030 & 38 \\
\hline$\frac{5}{5}$ & 1995 & 1181 & 4803 & 1 & 1493 & 65 \\
\hline 6 & 1905 & 2367 & 7031 & 2 & 3700 & 97 \\
\hline 7 & 1995 & 2254 & 15234 & 7 & 8762 & 77 \\
\hline 8 & 1995 & 7302 & 32846 & 5 & 7819 & 124 \\
\hline 9 & 1995 & 3664 & 14385 & 3 & 2658 & 95 \\
\hline 10 & 1995 & 1684 & 4288 & 0 & 0 & 33 \\
\hline 11 & 1995 & 379 & 2095 & 1 & 800 & 124 \\
\hline 12 & 1995 & 196 & 489 & 0 & 0 & 239 \\
\hline$A N O$ & 1995 & 29678 & 141098 & 26 & 31252 & 92 \\
\hline 1 & 1996 & 313 & 2062 & 0 & 0 & 251 \\
\hline 2 & 1096 & 199 & 367 & () & 0 & 87 \\
\hline 3 & 1996 & 1417 & 6563 & () & 0 & 88 \\
\hline 4 & 1996 & 903 & 2180 & 0 & () & 67 \\
\hline 5 & 1996 & 378 & 557 & 0 & 0 & 149 \\
\hline 6 & 1996 & 1584 & 2576 & 0 & 0 & 51 \\
\hline 7 & 1996 & 3337 & 15117 & 8 & 5602 & 100 \\
\hline 8 & 1996 & 3624 & 7317 & Q & 0 & 157 \\
\hline 9 & 1906 & 5575 & 18789 & 2 & 1358 & 149 \\
\hline 10 & 1996 & 1127 & 2691 & 0 & () & 57 \\
\hline 11 & 1996 & 183 & 614 & 0 & 0 & 134 \\
\hline 12 & 1996 & 93 & 96 & 0 & 0 & 270 \\
\hline ANQ & 1996 & 18733 & 58929 & 10 & 6960 & 135 \\
\hline 1 & 1997 & 114 & 267 & 0 & & 179 \\
\hline 2 & 1997 & 1078 & 7991 & 0 & & 14 \\
\hline 3 & 1997 & 9192 & 53209 & 4 & 2566 & 5 \\
\hline 4 & 1997 & 4600 & 22332 & 2 & {$[406$} & 77 \\
\hline 5 & 1997 & 754 & 2088 & 0 & & 149 \\
\hline 6 & 1007 & 473 & 1367 & 0 & & 151 \\
\hline 7 & 1997 & 1646 & 1588 & 0 & & $19 \overline{1}$ \\
\hline 8 & 1997 & 2246 & 2758 & 2 & 7088 & 229 \\
\hline 9 & 1997 & 3495 & 2842 & () & & 132 \\
\hline 10 & 1997 & 1900 & 3937 & () & & 82 \\
\hline II & 1997 & 69 & 96 & 0 & & 218 \\
\hline 12 & 1997 & 27 & 28 & () & & 187 \\
\hline ANO & 1997 & 25684 & 98503 & 8 & 11060 & \\
\hline 1 & 1998 & 328 & 1094 & 0 & & $\overline{74}$ \\
\hline 2 & 1998 & 2054 & $7[133$ & 1 & 538 & 57 \\
\hline$\frac{5}{3}$ & 1998 & 4090 & 18305 & 3 & 3317 & 48 \\
\hline 4 & $1 \overline{998}$ & 319 & 1884 & 1 & 1450 & 138 \\
\hline 5 & 1998 & 510 & 498 & 0 & & 161 \\
\hline 6 & 1998 & 1011 & 2033 & 0 & & 59 \\
\hline 7 & 1998 & 2591 & 24383 & 4 & 19225 & 45 \\
\hline 8 & 1998 & 9669 & 52065 & 12 & 11663 & 90 \\
\hline 9 & 1998 & 2976 & 11549 & 1 & 2763 & 163 \\
\hline 10 & 1998 & 732 & 2837 & 0 & & 49 \\
\hline 11 & 1098 & 567 & 4901 & 2 & 1476 & 42 \\
\hline 12 & 1998 & 507 & 4578 & 1 & 1330 & 75 \\
\hline $\mathrm{ANO}$ & 1998 & 25354 & 131260 & 25 & 41762 & \\
\hline$\frac{1}{1}$ & 1999 & 836 & 6627,97 & 0 & & 64 \\
\hline 2 & 1909 & 2102 & 9190.27 & 1 & 660 & 45 \\
\hline 3 & 1990 & 2522 & 11303.6 & 2 & 3000 & 109 \\
\hline 4 & 1999 & 1630 & 5610,11 & 0 & & 83 \\
\hline 5 & 1909 & 564 & $1: 93.41$ & 0 & & 93 \\
\hline 6 & 1999 & 1403 & 3664,16 & 1 & 657 & 62 \\
\hline 7 & 1909 & 3161 & 11772,99 & 4 & 17761 & 118 \\
\hline$\overline{8}$ & 1999 & 4203 & 22209,23 & 4 & 6992 & 143 \\
\hline 9 & 1999 & 2786 & 7166,78 & 1 & 985 & 207 \\
\hline 10 & 1999 & 419 & 1240,98 & I & 910 & 190 \\
\hline II & 1999 & 291 & 466,83 & 0 & & 58 \\
\hline 12 & 1999 & 228 & 1233,32 & 0 & & 79 \\
\hline $\mathrm{ANO}$ & 1999 & 20145 & 81679,65 & 14 & 30965 & \\
\hline
\end{tabular}

Fuentes: Elaborado con datos de los informes anuales de la Dirección General de Protección de in Naturaleza (DGCN) para los incendios y del Calendario Meteorológico de cada año del Instituto Nacional de Meteorología (INM) del Ministerio de Medio Ambiente. Se ha utilizado el \% que la precipitación de cada mes representa respecto a la precipitación mensual media para resaltar su carácter comparativamente normal, seco o lluvioso, cuya relación con los incendios activos es más expresiva. 
